\title{
Body and mind: retention in antiretroviral treatment care is improved by mental health training of care providers in Ethiopia
}

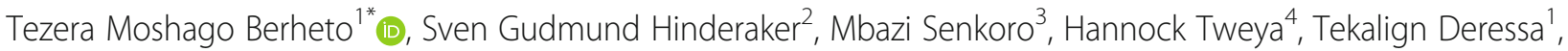
Yimam Getaneh ${ }^{1}$ and Gulilat Gezahegn ${ }^{5}$

\begin{abstract}
Background: Ethiopia has achieved a high coverage of antiretroviral treatment (ART), but maintaining lifelong care is still a great challenge. Mental illnesses often co-exist with HIV/AIDS and may compromise the retention on ART. In order to improve prolonged retention in ART care, basic training in mental health care was introduced for ART providers, but this hasn't been evaluated yet. The aim of this study was to examine if this training has improved patient retention in care.
\end{abstract}

Method: A retrospective cohort study was employed to compare attrition from ART between clients attended by care provider trained with basic mental health service (exposed) and those in the standard ART follow-up care (unexposed) in public health facilities. A routine patient follow-up electronic database enrolled for ART between 2005 and 2017 was abstracted for the study. The Kaplan-Meier plot was used to compare the attrition rates between the two groups. The log-rank test was used to assess differences in the groups. The Cox proportional hazards regression model was used to determine predictors of attrition. We used estimated effect size of hazard ratios (HR) with 95\% confidence intervals (Cl).

Result: During the 12 years of observation, 8009 study participants under ART were followed for 33,498 personyears. The incidence of attrition was 6.5 per 100 person-years and 21\% higher in the unexposed group (HR 1.21; $95 \% \mathrm{Cl} 1.1,1.3)$, and retention in care was significantly higher in the mental health exposed group throughout the study period. WHO clinical staging III/IV, tuberculosis coinfection, the male gender, and poor functional status were independent risk factors for attrition.

Conclusion: We found that clients in the group exposed to mental health care training tended to have better retention in ART care with some variation according to gender, WHO Clinical stage and functional status. Training of ART providers in mental health may be considered in order to strengthen ART retention in low resource settings.

Keywords: ART, Mental health care, Retention on care

\section{Background}

Generally, mental health problem and HIV/AIDS coexist with a complex bidirectional interaction [1-3]. Globally, mental health problems are more than twice as common among people living with HIV/AIDS (PLWH) as the general population $[4,5]$. There are several possible explanations for the higher prevalence of mental health problems among

\footnotetext{
* Correspondence: moshagot1@gmail.com

${ }^{1}$ Ethiopian Public Health Institute, HIV/AIDS and TB Research Directorate,

P.o.box 138, Wolaita Sodo Addis Ababa, Ethiopia

Full list of author information is available at the end of the article
}

PLWH. First, mental health problems such as depressive symptoms have been reported to be associated with HIV disease progression [6] and treatment outcome [7]. Second, mental health problems could be a manifestation of a direct effect of HIV on the brain cells $[8,9]$. Third, the strains of living with HIV/AIDS, as well as problems with poor sleep and chronic pain caused or aggravated by the illness, can also cause mental health problems [9]. Furthermore, beyond the disease process and the chronic conditions, the stigma and discrimination attached to this infection have been shown to augment the mental health problem [2, 9-11].

(c) The Author(s). 2018 Open Access This article is distributed under the terms of the Creative Commons Attribution 4.0 International License (http://creativecommons.org/licenses/by/4.0/), which permits unrestricted use, distribution, and reproduction in any medium, provided you give appropriate credit to the original author(s) and the source, provide a link to the Creative Commons license, and indicate if changes were made. The Creative Commons Public Domain Dedication waiver (http://creativecommons.org/publicdomain/zero/1.0/) applies to the data made available in this article, unless otherwise stated. 
In HIV patients, mental health problem can be a significant barrier to health behaviors such as retention in medical care and ART adherence, and thus pose a critical challenge for HIV care and control program [5, 7, 10]. A study of HIV-infected patients in Uganda, for example, revealed that $47 \%$ (95\% CI: 39-55\%) of patients with a mental health problem remained in care 12 months after ART initiation, compared to $65 \%$ (95\% CI: 61-69\%) of those without mental illness [10]. On the other hand, mental health support by providers has been reported to improve both retention in care and adherence among HIV patients [5, 7]. Therefore, mental health-related problems for HIV/AIDS patients who initiate ART may benefit from addressing such issues. However, in many countries including Ethiopia, this has not been properly recognized.

Ethiopia is one of the least developed countries in Africa that is severely affected by HIV/AIDS. The population in need of ART was estimated to be more than 770,000 in 2017 [11]. To ensure the accessibility of the care, the service has been decentralized to primary health care level since 2006 [11]. As a result, the service is available for a large part of the population in need. Furthermore, the country has launched the three 90s treatment target for HIV/AIDS prevention and control by 2020: $90 \%$ to know their HIV status, $90 \%$ of diagnosed HIV patients to receive ART, and $90 \%$ of HIV patients on ART to have viral suppression. Currently, high attrition rate, poor adherence to treatment regimen, and early mortality are prominent challenges of the HIV/ AIDS program in the country. Recent studies in Ethiopia indicated attrition to be around $20 \%$ at 6 months of follow-up [12, 13], which could foster poor treatment outcomes, emergence of drug resistance and potential transmission of drug-resistant virus strain.

Mental illness can aggravate adverse outcomes of ART [14, 15], and integration of mental health care into ART clinics was found to be effective in improving the ART outcomes [9]. Provision of ART has previously not focused much on the impact of mental illness, but the 2016 WHO consolidated guidelines for ART includes a section on treatment of mental health problems such as depression in clients on ART care packages. In Ethiopia, integration of mental health care into the ART clinics through the provision of basic training of mental health care for ART care providers has been implemented stepwise since 2005. However, the effectiveness of these training has not been evaluated.

Hence, the present study is aimed to determine the effect of basic mental health care training of ART providers on the outcome of ART in Ethiopian public health facilities.

\section{Methods}

\section{Study design}

A retrospective cohort study was employed to compare outcomes of ART between two different therapeutic approaches; care provider trained with basic mental health care and the standard ART follow-up care.

\section{Setting}

The study was conducted in Southern Nations, Nationalities and People regional states (SNNPRS) public health facilities providing ART service. This region is located in Southern parts of Ethiopia. It is the third most populous regional state in Ethiopia accounts for $20 \%$ of an estimated 103 million people. The region is administratively divided into 15 zones, three special districts, and one city administration. The Ministry of Health of Ethiopia follows a three-tier healthcare system, including a few private health care facilities concentrated in urban areas. The ART is provided free of direct cost mainly in public health facilities, but also in selected private ones. The ART program is directed centrally from the ministry of health, all the health facilities in the country follow similar modalities and national guidelines, which are developed based on the WHO guidelines. Usually, the ART clients visit health care facilities bimonthly in the early phase of the care and then every two to three months appointment based on the client's adjustment to treatment adherence. On-demand visit is always open if the need arises from the client side. The National Mental Health Strategy is expanding the integration of mental health services into HIV follow-up clinic throughout the country through training of basic mental health care for the non-specialist care provider, with the first training in 2005.

In the SNNPRS two zones were selected to study based on similar sociodemographic characteristics, setting, and the level and timing of initiating the training of the basic mental health care. All the public health facilities were categorized as "exposed" or "not exposed" to mental health training by a panel of experts in the health departments, based on their knowledge of plans, processes, and progress. Criteria for categorizing as "exposed" facility were whether ART providers received basic mental health care training. Patients who had moved from a non-exposed facility to an exposed or vice versa were excluded. Out of 25 public facilities, we selected purposefully three exposed and five unexposed facilities. ART care providing facilities with care providers recently trained with basic mental health care training and/or interrupted service due to staff turnover and failure to sustain the integrated service were excluded.

\section{Specific settings}

The study was conducted in seven health facilities: three exposed facilities (Bue Health Center, Butajira Hospital and Butajira Health center); and four facilities (Sodo Health center, Sodo General Hospital, Atat Hospital and Wilkeite Health Center) where the care providers were unexposed. The facilities in the exposed part are supported by the PRIME-Ethiopia project of Addis Ababa 
University, Department of psychiatry by training the care providers.

\section{Study population}

The study population included all HIV infected people enrolled for ART care between January 2005 and May 2017 in public health facilities in the study area.

\section{Description of the mental health care intervention package}

ART care providers (nurses, health officers, physicians, and psychologist) in the integrated facility have received a seven days additional basic mental health care training to diagnose mental health problems and either to treat patients with basic psychotropic medications or refer them to an area hospital that provides psychiatric services. The overall goals of the training are (1) to enable primary health providers to work together in teams to recognize mental health problems among individuals receiving HIV care, and to deliver brief, first line interventions; (2) to enable primary health providers to collaborate with mental health specialists (nurses, psychologists, social workers, and psychiatrists) in the evaluation and treatment of mental health problems among individuals receiving HIV care; (3) to be familiar with the many different ways in which people with mental health problems can be helped; and (4) to be familiar with "stepped" approaches based on response to initial treatment and follow-up. The training includes the following topics: communication skills and assessment,

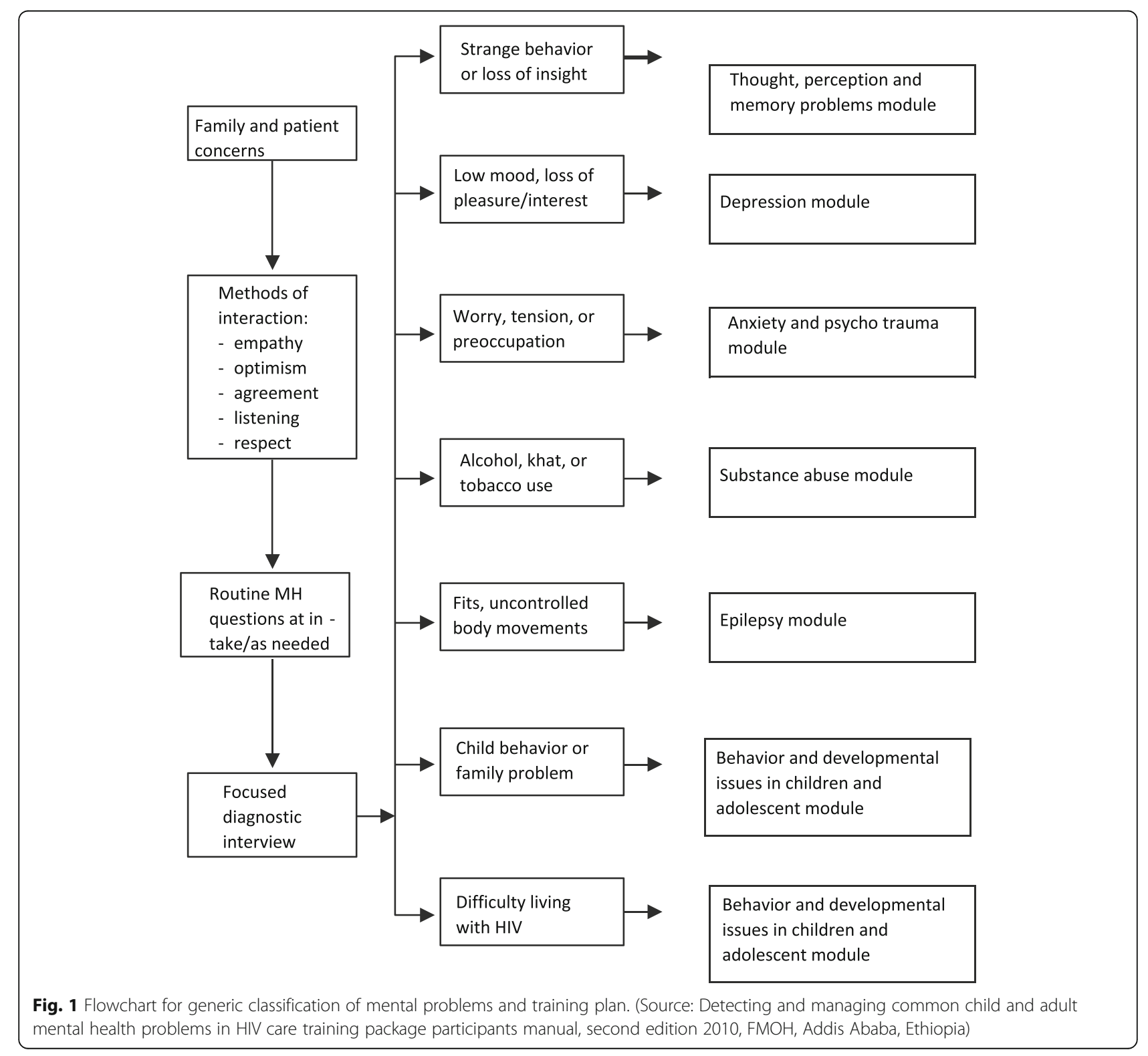


thought, perception, memory problems, depression, anxiety, psychotrauma, substance abuse, epilepsy, behavior and developmental issues in children and adolescents, mental health aspects of living with HIV, and implementation issues (Fig.1 ).

The identified psychotropic medications from the essential drug list and targeted conditions were: haloperidol, chlorpromazine amitriptyline, fluoxetine diazepam, bromazepam, phenobarbital, phenytoin, carbamazepine. Memory loss/dementia is treated with ARVs, and substance abuse is treated with counseling. According to the Sodo district health department, all ART care providers were trained during 2005 and 2006 fiscal years, and it's being given to new recruits continuously. The ART regimens used by the program are standardized [11].

\section{Data variables, sources of data and data collection \\ Data}

We used the data collected routinely in HIV/AIDS clinic for patient monitoring and evaluation purposes. The main outcome variable was attrition a combination of LTFU, death and discontinued. As determinants of retention in ART, we assessed age, gender, TB-co infection, CD4 cell count, WHO clinical stage, INH prophylaxis, Cotrimoxazole supplement, provision of mental health service, adverse drug reaction.

\section{Definitions of variables}

The following operational definitions were used in this study. Lost to follow-up (LTFU): clients who missed scheduled clinical appointments for more than 90 days in a calendar year. Retained in care: clients who were on ART at the end of the study follow-up. Attrition: Clients who were recorded as LTFU, discontinued the ART, died after initiation of the ART care within the study period. Discontinued: clients known to have abrupted ART for any clinical or personal reason. Died: a patient who died after initiation of the ART regardless of the causes of death.

\section{Analysis and statistics}

The data were routinely collected in the facility for clinical monitoring and evaluation, and entered into the national ART registration database in each facility with a unique identification number. Health personnel working in the clinic recorded all the data. Data recording started from the date that patients started regular HIV care in the clinic to confirmation of the final event. The database recorded was exported into Microsoft Excel, checked for inconsistencies and completeness, and then cleaned. Statistical analysis was done using R 3.4.2 (Comprehensive R Archive Network) and Stata Statistical Software (Release 14. College Station, TX: StataCorp LP).
The time to attrition was calculated in months according to the time interval between the dates of ART initiation to the occurrence of the event of interest (death, loss to follow-up or discontinuation), as recorded by the ART registration personnel. Patient characteristics were described in terms of mean, median or percentage, as appropriate. In order to account for changes in eligibility criteria for protocols of ART initiation to the year of the major change effected was used for analytic adjustments. Kaplan-Meier

Table 1 Baseline and follow-up characteristics of participants under ART with mental health trained and non-trained providers, Ethiopia

\begin{tabular}{|c|c|c|c|}
\hline \multirow[t]{2}{*}{ Characteristics } & \multicolumn{3}{|l|}{ Facility category } \\
\hline & Exposed n (\%) & Unexposed n (\%) & $P$ value \\
\hline \multicolumn{4}{|l|}{ ART Enrolment year } \\
\hline 2005-2007 & $408(22.1)$ & 1569 (25.6) & \multirow[t]{4}{*}{0.08} \\
\hline 2008-2010 & $639(34.6)$ & $2179(35.5)$ & \\
\hline 2011-2013 & $433(23.4)$ & $1244(20.3)$ & \\
\hline 2014-2017 & $369(20.0)$ & 1138 (18.6) & \\
\hline \multicolumn{4}{|l|}{ Gender } \\
\hline Male & $747(40.3)$ & $2602(42.3)$ & \multirow[t]{3}{*}{0.13} \\
\hline Female & $1107(59.7)$ & $3553(57.7)$ & \\
\hline total & $1854(23.1)$ & $6155(76.9)$ & \\
\hline \multicolumn{4}{|l|}{ WHO stage at entry } \\
\hline Stage I & $408(24.3)$ & $1272(20.9)$ & \multirow[t]{4}{*}{0.01} \\
\hline Stage II & $348(19.1)$ & $1592(26.1)$ & \\
\hline Stage III & $866(47.5)$ & $2600(42.6)$ & \\
\hline Stage IV & $203(11.1)$ & $634(10.4)$ & \\
\hline \multicolumn{4}{|l|}{ Functional status at entry } \\
\hline Bedridden & $130(7.3)$ & $353(5.9)$ & \multirow[t]{3}{*}{0.07} \\
\hline Ambulatory & $580(32.5)$ & $1515(25.3)$ & \\
\hline Working & $1072(60.2)$ & $4116(68.8)$ & \\
\hline \multicolumn{4}{|l|}{ TB Coinfection } \\
\hline No (-ve) & $1467(79.1)$ & $5138(83.5)$ & \multirow[t]{2}{*}{0.01} \\
\hline Yes (+ve) & $387(20.9)$ & $1017(16.5)$ & \\
\hline \multicolumn{4}{|l|}{ INH prophylaxis } \\
\hline Yes & $865(46.7)$ & $3222(52.3)$ & \multirow[t]{2}{*}{0.01} \\
\hline No & $989(53.3)$ & $2933(47.7)$ & \\
\hline \multicolumn{4}{|l|}{ Ever Regimen Substitution } \\
\hline No & $1326(71.5)$ & $4503(73.2)$ & \multirow[t]{2}{*}{0.23} \\
\hline Yes & $528(28.5)$ & $1652(26.8)$ & \\
\hline \multicolumn{4}{|l|}{ Ever Regimen Switch } \\
\hline No & $1819(98.1)$ & $6101(99.1)$ & \multirow[t]{3}{*}{0.01} \\
\hline Yes & $35(1.9)$ & $54(0.9)$ & \\
\hline Viral load Test $(n=1512)$ & 270 & 1242 & \\
\hline Detectable & $41(15.2)$ & $305(24.6)$ & \multirow[t]{2}{*}{0.01} \\
\hline Not Detectable & $229(84.8)$ & $937(75.4)$ & \\
\hline
\end{tabular}


Table 2 Retention in ART care during follow-up attending exposed and unexposed ART providers in Ethiopia

\begin{tabular}{|c|c|c|c|c|}
\hline \multirow{3}{*}{$\begin{array}{l}\text { Follow-up } \\
\text { time in month }\end{array}$} & & & & \\
\hline & \multicolumn{2}{|c|}{$\begin{array}{l}\text { Cumulative probability }(95 \% \mathrm{Cl}) \text { of retention in care } \\
\text { after attrition from deaths }\end{array}$} & \multicolumn{2}{|c|}{$\begin{array}{l}\text { Cumulative probability }(95 \% \mathrm{Cl}) \text { of retention in care } \\
\text { after any attrition }\end{array}$} \\
\hline & Exposed & Unexposed & Exposed & Unexposed \\
\hline 6 & $94.5(93.4,95.5)$ & $95.4(94.8,95.9)$ & $92.4(91.1,93.6)$ & $90.9(90.1,91.6)$ \\
\hline 12 & $92.1(90.8,93.3)$ & $93.5(92.8,94.1)$ & $88.1(86.4,89.5)$ & $84.5(83.6,85.4)$ \\
\hline 18 & $90.6(89.1,91.9)$ & $93.0(92.3,93.7)$ & $86.0(84.3,87.6)$ & $81.2(80.1,82.2)$ \\
\hline 24 & $89.6(88,90.9)$ & $92.6(91.86,93.3$ & $84.3(82.5,86.0)$ & $79.1(78.0,80.1)$ \\
\hline 48 & $82.9(80.8,84.8)$ & $90.8(89.93,91.6)$ & $76.9(74.6,78.9)$ & $73.3(72.0,74.5)$ \\
\hline 144 & $73.2(68.4,77.4)$ & $81.3(77.5,84.6)$ & $63.3(58.6,67.6)$ & $52.6(47.3,57.5)$ \\
\hline
\end{tabular}

$\mathrm{Cl}$ Confidence interval); Exposed Exposed to mental health care

plots were used to compare attrition rates between "exposed" and "unexposed" clients. The log-rank test was used to compare the two groups. Multivariable Cox proportional hazards regression models with clustered robust estimates to account for an inter health-facility correlation were used to identify the independent effect of mental health service and other predictors of attrition. We used estimated effect size of hazard ratios (HR) with $95 \%$ confidence intervals $(\mathrm{CI})$.

\section{Results}

Between 2005 and 2017, a total of 8009 study participants under ART were followed. Of them, 1854 (23.1\%) were followed by providers who exposed to mental health services. About 59.7\% (1107) of patients followed by the exposed group were women. They were followed for 33,498-person-years. The median follow-up duration was 42 with interquartile range (IQR) of 13 to 85 months for mental health service exposed and 38 (IQR 11, 85) months for unexposed.

The median age of the participants in exposed groups was 31 (IQR 25, 38) years and 33 (IQR 24, 39) years for un-exposed. The median CD4 count at the start of ART was 171 (IQR 87, 261cells $/ \mathrm{mm}^{3}$ ) among exposed and 172 (IQR 93, 272) among unexposed. TB-HIV co-infection was present in 387 (20.9\%) of the exposed and 1017 (16.5\%) of unexposed participants in the follow-up period.

By the end of the follow-up, excluding the patients transferred to another place, 968 (52\%) of exposed clients and $2753(44.7 \%)$ of unexposed were retained in care. Treatment outcomes reported were as follows in the exposed versus (vs) the unexposed groups: died 297 (16\%) vs $550(8.9 \%)$, drop out 140 (7.6\%) vs1125 (18.3\%) and transfer out 438 (23.6\%) vs 1648 (26.8\%). There were no statistically significant differences between the two groups in baseline demographic, ART regimen (including efavirenz) and CD4 cell count. The regimen was changed in 528 (28.5\%) of the exposed participant, and $1652(26.8 \%)$ of the unexposed participants (Table 1).
The overall incidence rate of attrition was 6.5 per 100 person-years and was higher in unexposed than exposed (HR 1.21; 95\% CI 1.1, 1.3). The overall attrition rate from ART gradually declined with duration of treatment. The probability of retention (95\% CIs) on ART at the 6th, 12th, and 24th months is shown in Table 2.

The Kaplan Meier plots (Fig. 2) and (Table 2) revealed that clients exposed to mental health service had higher overall retention in care than the unexposed, but the number of a verified death was higher in the exposed group.

\section{Factors associated with the attrition from ART}

Controlling for other demographic and clinical characteristics in a Cox-proportional hazard regression analysis, mental health service exposure had significantly increased retention in care, and the risk of attrition in the unexposed group was $20 \%$ higher than the exposed group (HR 1.2; 95\% CI 1.1-1.4). Furthermore, age, advanced WHO clinical staging, not using cotrimoxazole

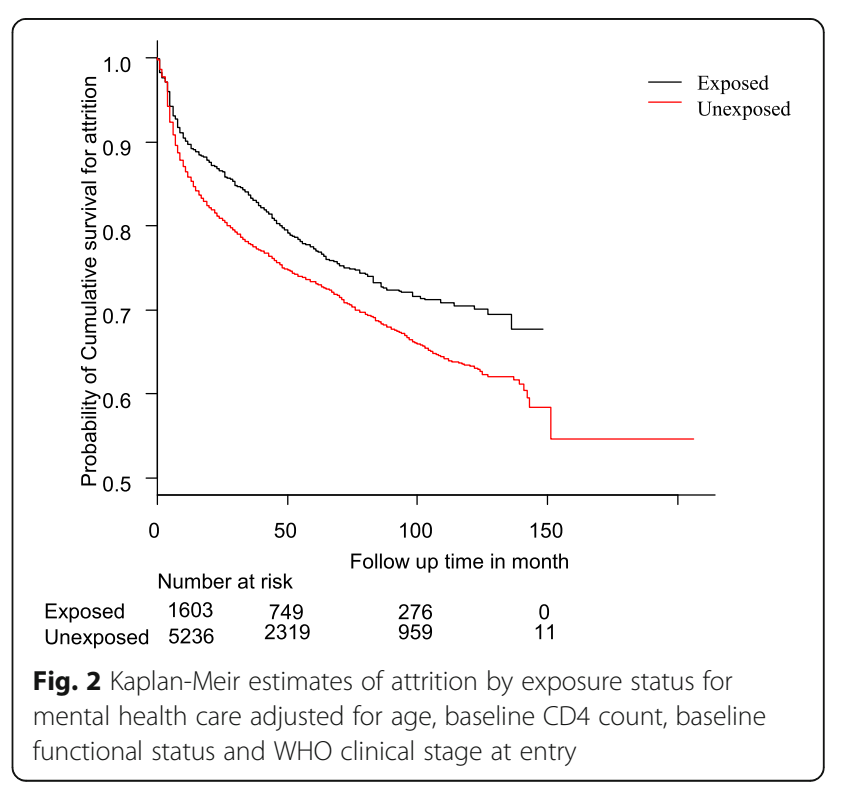


prophylaxis, TB-coinfection, not getting isoniazid prophylaxis, male gender, and functional status were independent risk factors for outcomes of ART (Table 3).

\section{Discussion}

This study confirmed the hypothesis that basic mental health care service training for ART care providers improved patient retention in care. Patient under ART from facilities with ART providers trained on basic

Table 3 Analysis of factors associated with attrition among HIV infected patients Under ART in South Ethiopia

\begin{tabular}{|c|c|c|}
\hline Variables & Attrition n (\%) & $\operatorname{AHR}(95 \% \mathrm{Cl})$ \\
\hline \multicolumn{3}{|l|}{ Mental health } \\
\hline Unexposed & $1750(79.6)$ & $1.2(1.1,1.4)$ \\
\hline Exposed & $1063(48.4)$ & Ref \\
\hline Age (IQR) & $31.75(11.13)$ & $0.9(0.99,1.0)$ \\
\hline BaseCD4count (IQR) & $220.51(760.59)$ & $0.9(0.95,1.0)$ \\
\hline \multicolumn{3}{|l|}{ Baseline WHO clinical } \\
\hline WHO stage [l] & 298 (13.9) & Ref \\
\hline WHO stage [II] & $421(19.6)$ & $1.1(0.9,1.3)$ \\
\hline WHO stage [III] & $1042(48.5)$ & $1.2(1.01,1.4)$ \\
\hline WHO stage [IV] & $386(18)$ & $1.5(1.2,1.8)$ \\
\hline \multicolumn{3}{|l|}{ CTM prophylaxis } \\
\hline (No) & $314(14.3)$ & $1.2(1.01,1.3)$ \\
\hline Yes & $1884(85.7)$ & Ref \\
\hline INH prophylaxis & $445(20.2)$ & $0.2(0.14,0.2)$ \\
\hline \multicolumn{3}{|l|}{ (Yes) } \\
\hline No & $1753(79.8)$ & Ref \\
\hline \multicolumn{3}{|l|}{ TB Coinfection } \\
\hline (Yes) & $455(20.7)$ & Ref \\
\hline No & $1743(79.3)$ & $0.7(0.6,0.7)$ \\
\hline \multicolumn{3}{|l|}{ Gender } \\
\hline Female & 1135 (51.6) & Ref \\
\hline Male & $1063(48.4)$ & $1.2(1.1,1.3)$ \\
\hline LowestCD4 (IQR) & $164.05(163.07)$ & $0.9(0.9,0.99)$ \\
\hline Regimen Substitution (No) & 1845 (83.9) & $0.14(0.12,0.2)$ \\
\hline Substitution (yes) & $353(16.1)$ & Ref \\
\hline \multicolumn{3}{|l|}{ Baseline functional status } \\
\hline Working & 1135 (51.6) & $0.6(0.5,0.7)$ \\
\hline Ambulatory & $726(33.0)$ & $0.5(0.4,0.5)$ \\
\hline Bedridden & $280(12.7)$ & Ref \\
\hline \multicolumn{3}{|l|}{ ART Enrolment year } \\
\hline 2005-2007 & $610(28)$ & Ref \\
\hline 2008-2010 & $830(38.2)$ & $1.22(1.1,1.36)$ \\
\hline 2011-2013 & 435 (20) & $1.5(1.31,1.73)$ \\
\hline 2014-2017 & 300 (13.8) & $2.3(1.962 .75)$ \\
\hline
\end{tabular}

'Analyzed by Cox proportional hazard regression, with adjusted hazard ratio (AHR) with $95 \%$ confidence interval mental health care tended to be retained longer. The risk of attrition from the ART care was $20 \%$ higher in facilities unexposed to mental health services as compared to facilities exposed to mental health care. A considerable proportion of the attrition occurred in the first six months of ART initiation.

Proper patient/provider relationships and clinic experiences are known to improve patients' trust on care providers and can significantly impact retention and adherence of patients. Therefore, the overall better retention of clients observed in the exposed group could be a result of a better counseling of patients on drug adherence, coping mechanisms with drug adverse effects, and mental health problems such as depression and anxiety which may jeopardize the success of ART. The effect may be partly due to the training of ART providers in mental health packages.

Consistent with our findings, studies indicated that behavioral intervention, which is considered as a part of the counseling package, had improved the adherence to ART treatment, viral suppression, and an overall outcome of ART. Furthermore, a meta-analysis that evaluated the efficacy of behavioral interventions for alcohol abuse, a major health problem among PLWH, indicated a significant improvement in HIV-related health outcomes [16-18]. Considering these, our finding has important implications for current ART care in Ethiopia and underscores the need for integration of mental health care into ART clinics to improve treatment outcomes.

The overall Kaplan-Meir estimates of retention show that the largest attrition occurred in the first year. The probability of retention in the unexposed group was comparable with other studies conducted in Ethiopia [12, 13]. Retention in care in the exposed groups from the present study seem to be higher than other studies in a similar setting unexposed for mental health care [13, 19].

The causes of attrition in the present study were significantly different between the two groups. In the exposed group, attrition was mainly from verified death whereas LTFU was found to be the major cause for attrition in the unexposed group. The later was in agreement with the existing evidence $[12,13,20]$. Different studies indicated that in low resource setting with poor vital registration system like in Ethiopia, deaths, and causes of death are not reported. A meta-analysis of the LTFU patients in Africa revealed that 12 to $87 \%$ were due to death [21]. Thus, most of the LTFU clients would have died but pass unnoticed and are categorized incorrectly as a loss-to-follow-up. Due to a possible enhanced client counseling and better communication, it is possible that the probability of identifying the true outcome of LTFU in the exposed group might be higher than in the unexposed group. However, more rigorous research is needed to establish the relationship between the basic training of mental health care for PLHIV and the improvement in the outcome of ART. 
In this study, we found that male gender has $20 \%$ higher attrition rate as compared with women. Some reports find no significant difference [12], but the majority of the existing evidence indicates that in ART women have better outcomes than men [13, 21, 22]. This could be due to several reasons, including different lifestyle between the two genders; males use more alcohol; and different coping thresholds. This study also found that subjects with a history of TB-coinfection were at higher risk for attrition from ART. This is consistent with other studies [12, 22]. TB is a known coinfection and major causes of AIDS-related death. ART client not getting INH prophylaxis, not using CTM prophylaxis were associated with better experiences of retention in care. This may be confounded by the eligibility criteria for the prophylaxis. People highly vulnerable to opportunistic infection are usually eligible for the prophylaxis.

Bed ridden and ambulatory patients were at higher risk for attrition from ART. In line with this data, evidences indicate that a baseline advanced disease progression was associated with higher risk of attrition [23, 24]. These suggest that being at poor clinical condition could be the contributing factor for the higher attrition rate.

\section{Strength and limitation}

The strength of this study was the large sample size and the long duration in both mental health services exposed and unexposed groups. Another strength is that this is "real life" situation reflecting realities in public health in the districts studied. We also think that this may have a positive impact on the awareness of mental health and their often-neglected services in the country.

One limitation of the study is that we did not have any measurement of the level of mental health care training. Thus, the effect of this training on the magnitude of mental health disorders deserves a separate study. Furthermore, this study analysed the retrospective records of patients; and the accuracy of this data depends on the data collection and recording systems of the facilities. Some misclassification of exposure to $\mathrm{MH}$ training is obviously possible, with consequences for the results; however, it is probably minimal as the classification was done by individuals responsible and close to the program with a likely correct appraisal.

\section{Conclusion}

In conclusion, better retention in care was found among the clients of ART care providers who got basic mental health care training. However, there was some variation according to gender, baseline progress of the disease WHO Clinical stage and functional status. Training of ART providers in mental health may be considered in order to improve ART outcomes in low resource settings.

\section{Abbreviations}

AHR: Adjusted hazard ratio; AIDS: Acquired immune deficiency syndrome; ART: Antiretroviral treatment; CTM: Cotrimoxazole; HIV: Human immunodeficiency virus; LTFU: Loss to follow-up; PLHIV: People living with HIV; WHO: World Health Organization

\section{Acknowledgements}

This research was conducted through the Structured Operational Research and Training Initiative (SORT IT), a global partnership led by the Special Programme for Research and Training in Tropical Diseases at the World Health Organization (WHO/TDR). The training model is based on a course developed jointly by the International Union Against Tuberculosis and Lung Disease (The Union) and Medécins sans Frontières (MSF). The specific SORT IT program which resulted in this publication was implemented by: Medécins Sans Frontières, Brussels Operational Center, Luxembourg and the Centre for Operational Research, The Union, Paris, France. Mentorship and the coordination/facilitation of these SORT IT workshops were provided through the Centre for Operational Research, The Union, Paris, France; the Operational Research Unit (LuXOR); AMPATH, Eldoret, Kenya; The Institute of Tropical Medicine, Antwerp, Belgium; The Centre for International Health, University of Bergen, Norway; and The National Institute for Medical Research, Muhimbili Medical Research Centre, Dar es Salaam, Tanzania.

\section{Funding}

The program was funded by the United Kingdom's Department for International Development (DFID), The Union, MSF and La Fondation Veuve Emile Metz-Tesch (Luxembourg). La Fondation Veuve Emile Metz-Tesch supported open access publications costs. The data collection and local transportation was financially supported by Wolaita Sodo University. The funders had no role in study design, data collection and analysis, decision to publish, or preparation of the manuscript.

\section{Availability of data and materials}

The dataset analysed for the findings of this study are available with the corresponding author and can accessed by reasonable request.

\section{Authors' contributions}

TMB, Conceived the study. TMB, SG, HT, and MS designed the study, performed the statistical analysis and wrote up the manuscript. TMB, SG, TD, YG, MS and GG further developed the manuscript to scientific standard. All authors read and approved the final manuscript.

\section{Ethics approval and consent to participate}

Permission to carry out the study was obtained from Wolaita Sodo University IRB. Local ethics approval was obtained from SNNPRS health bureau and each zonal health department. This research fulfilled the exemption criteria set by the Médecins Sans Frontières Ethics Review Board for a posteriori analyses of routinely collected clinical data and thus did not require MSF IRB review. It was conducted with permission from the Medical Director, Operational Centre Brussels, Médecins Sans Frontières.

The study was also approved by the Ethics Advisory Group of the International Union against Tuberculosis and Lung Disease, Paris, France. As this was a record review study, informed patient consent was not required. Through written permission from regional health authorities the databases were accessed in respective health care facilities after informed verbal consent of medical heads of health facilities. Confidentiality of the records was maintained.

\section{Consent for publication}

Not applicable.

\section{Competing interests}

The authors declare that they have no competing interests.

\section{Publisher's Note}

Springer Nature remains neutral with regard to jurisdictional claims in published maps and institutional affiliations.

\section{Author details}

${ }^{1}$ Ethiopian Public Health Institute, HIV/AIDS and TB Research Directorate, P.o.box 138, Wolaita Sodo Addis Ababa, Ethiopia. ${ }^{2}$ Centre for international 
Health, University of Bergen, Bergen, Norway. ${ }^{3}$ National Institute for Medical Research, Muhimbili Medical Research Centre, Dare Selam, Tanzania. ${ }^{4}$ Medecins Sans Frontieres, Medical Department (Operational Research) Brussels Operational Center, Luxembourg, Luxembourg. ${ }^{5}$ Guraghe Zonal Health Department, Disease Prevention and Control Unit, Wolkite, Ethiopia.

Received: 19 December 2017 Accepted: 10 July 2018

Published online: 20 July 2018

\section{References}

1. Chipimo PJ, Fylkesnes K. Mental distress in the general population in Zambia: impact of HIV and social factors. BMC Public Health. 2009;9(1):298.

2. Chambers LA, Rueda S, Baker DN, Wilson MG, Deutsch R, Raeifar E, Rourke SB. Stigma, HIV and health: a qualitative synthesis. BMC Public Health. 2015;15(1):848.

3. Egbe CO, Dakum PS, Ekong E, Kohrt BA, Minto JG, Ticao CJ. Depression, suicidality, and alcohol use disorder among people living with HIV/AIDS in Nigeria. BMC Public Health. 2017;17(1):542.

4. Freeman M, Nkomo N, Kafaar Z, Kelly K. Mental disorder in people living with HIV/AIDS in South Africa. S Afr J Psychol. 2008;38(3):489-500.

5. Sherr L, Clucas C, Harding R, Sibley E, Catalan J. HIV and depression - a systematic review of interventions. Psychol Health Med. 2011;16(5):493-527.

6. Antelman G, Kaaya S, Wei R, Mbwambo J, Msamanga Gl, Fawzi WW, Fawzi MCS. Depressive symptoms increase risk of HIV disease progression and mortality among women in Tanzania. JAIDS J Acquir Immune Defic Syndr. 2007:44(4):470-7.

7. Okeke EN, Wagner GJ. AIDS treatment and mental health: evidence from Uganda. Soc Sci Med (1982). 2013;92:27-34.

8. Perkins Diana O, Leserman J, Stern RA, Baum SF. Somatic symptoms and HIV infection: relationship to depressive symptoms and indicators of HIV disease. Am J Psychiatr. 1995;152(12):1776-81.

9. Brandt R. The mental health of people living with HIV/AIDS in Africa: a systematic review. Afr J AIDS Res. 2009;8(2):123-33.

10. Nachega JB, Mutamba B, Basangwa D, Nguyen H, Dowdy DW, Mills EJ, Katabira E, Nakimuli-Mpungu E. Severe mental illness at ART initiation is associated with worse retention in care among HIV-infected Ugandan adults. Tropical Med Int Health. 2013;18(1):53-7.

11. Ethiopian Menistery Of Health: Comperhensive quidelines on the use of antiretroviral drugs. 2015.

12. Berheto TM, Haile DB, Mohammed S. Predictors of loss to follow-up in patients living with HIV/AIDS after initiation of antiretroviral therapy. N Am J Med Sci. 2014;6(9):453.

13. Bucciardini R, Fragola V, Abegaz T, Lucattini S, Halifom A, Tadesse E, Berhe $M$, Pugliese K, Fucili L, Gregorio MD, et al. Predictors of attrition from care at 2 years in a prospective cohort of HIV-infected adults in Tigray, Ethiopia. BMJ Global Health. 2017;2(3):e000325.

14. Ciesla JA, Roberts JE. Meta-analysis of the relationship between HIV infection and risk for depressive disorders. Am J Psychiatr. 2001;158(5):725-30.

15. Collins PY, Holman AR, Freeman MC, Patel V. What is the relevance of mental health to HIV/AIDS care and treatment programs in developing countries? A systematic review. AIDS (London, England). 2006:20(12):1571.

16. Whetten K, Reif S, Whetten R, Murphy-McMillan LK. Trauma, mental health, distrust, and stigma among HIV-positive persons: implications for effective care. Psychosom Med. 2008;70(5):531-8.

17. Pappin $\mathrm{M}$, Wouters $\mathrm{E}$, Booysen FL. Anxiety and depression amongst patients enrolled in a public sector antiretroviral treatment programme in South Africa: a cross-sectional study. BMC Public Health. 2012;12(1):244.

18. Holtzman CW, Brady KA, Yehia BR. Retention in care and medication adherence: current challenges to antiretroviral therapy success. Drugs. 2015; 75(5):445-54.

19. Hassan AS, Mwaringa SM, Ndirangu KK, Sanders EJ, de Wit TFR, Berkley JA. Incidence and predictors of attrition from antiretroviral care among adults in a rural HIV clinic in coastal Kenya: a retrospective cohort study. BMC Public Health. 2015:15(1):478.

20. Somi G, Keogh S, Todd J, Kilama B, Wringe A, Van Den Hombergh J, Malima K, Josiah R, Urassa M, Swai R. Low mortality risk but high loss to follow-up among patients in the Tanzanian national HIV care and treatment programme. Tropical Med Int Health. 2012;17(4):497-506.

21. Abioye A, Soipe A, Salako A, Odesanya M, Okuneye T, Abioye A, Ismail K, Omotayo M. Are there differences in disease progression and mortality among male and female HIV patients on antiretroviral therapy? A metaanalysis of observational cohorts. AIDS Care. 2015;27(12):1468-86.
22. Mutasa-Apollo T, Shiraishi RW, Takarinda KC, Dzangare J, Mugurungi O, Murungu J, Abdul-Quader A, Woodfill CJI. Patient retention, clinical outcomes and attrition-associated factors of HIV-infected patients enrolled in Zimbabwe's National Antiretroviral Therapy Programme, 2007-2010. PLoS One. 2014;9(1):e86305.

23. van der Kop M, Ekström A, Awiti-Ujiji O, Chung M, Mahal D, Thabane L, Gelmon L, Kimani J, Lester R. Factors associated with attrition from HIV care during the first year after antiretroviral therapy initiation in Kenya. J AIDS Clin Res. 2014;5(10).

24. Okoboi S, Ssali L, Yansaneh Al, Bakanda C, Birungi J, Nantume S, Okullu JL, Sharp AR, Moore DM, Kalibala S. Factors associated with long-term antiretroviral therapy attrition among adolescents in rural Uganda: a retrospective study. J Int AIDS Soc. 2016;19(5Suppl 4):20841.
Ready to submit your research? Choose BMC and benefit from:

- fast, convenient online submission

- thorough peer review by experienced researchers in your field

- rapid publication on acceptance

- support for research data, including large and complex data types

- gold Open Access which fosters wider collaboration and increased citations

- maximum visibility for your research: over $100 \mathrm{M}$ website views per year

At BMC, research is always in progress.

Learn more biomedcentral.com/submissions 